\title{
Urodimento
}

REVISTA DE ESTUDOS EM ARTES CÊNICAS

E-ISSN 2358.6958

\section{Laboratórios de criação no meio do caos pandêmico: Visualidades e os figurinos da personagem negra}

Carla Aparecida Costa

Para citar este artigo:

COSTA, Carla Aparecida. Laboratórios de criação no meio do caos pandêmico: Visualidades e os figurinos da personagem negra. Urdimento - Revista de Estudos em Artes Cênicas, Florianópolis, v. 2, n. 41, set. 2021.

doi DOl: http:/dx.doi.org/10.5965/1414573102412021e0302

Este artigo passou pelo Plagiarism Detection Software| iThenticate 


\title{
Resumo
}

Carla Aparecida Costa²

A espera pelo acontecimento, a busca pela criação com ética e com respeito à história e trajetória da personagem negra. Esse texto traz a experiência vivida em sala de aula e as expectativas de como criar figurinos para e sobre temáticas negras. Apresentamos aqui fatos ocasionados pela pandemia e a superação do corpo discente que em meio ao caos buscou forças para criar e projetar figurinos para a personagem negra que por muitos séculos foi invisibilizada nos palcos dos teatros brasileiros. O relato apresentado faz parte da tese de doutorado que está em fase de pesquisa.

Palavras-chave: Pandemia. Processo de Criação. Figurino.

\section{Creation laboratory in the midst of pandemic chaos: \\ Visualities and costumes of the black character}

\begin{abstract}
The wait for the event, the search for creation with ethics and respect for the history and trajectory of the black character. This account brings the experience lived in the classroom and the expectations of how to create costumes for and about black bodies. Here we present facts caused by the pandemic and the overcoming of the student body that, amidst the chaos, sought strength to create and design costumes for the black character who for many centuries was invisible on the stages of Brazilian theaters. The report presented is part of the doctoral thesis that is in the research phase.
\end{abstract}

Keywords: Pandemic. Creation process. Costume.

\section{Laboratorio de creación en medio del caos pandémico: \\ Visualidades y vestuarios del personaje negro}

\section{Resumen}

La espera del evento, la búsqueda de la creación con ética y respeto a la historia y trayectoria del personaje negro. Este relato trae la experiencia vivida en el aula y las expectativas de cómo crear disfraces para y sobre cuerpos negros. Aquí presentamos hechos provocados por la pandemia y la superación del alumnado que, en medio del caos, buscó la fuerza para crear y diseñar el vestuario del personaje negro que durante muchos siglos fue invisible en los escenarios de los teatros brasileños. El informe presentado forma parte de la tesis doctoral que se encuentra en fase de investigación.

Palabras llave: Pandemia. Proceso de creación. Disfraz.

\footnotetext{
${ }^{1}$ Revisão do texto feita por Fernanda De Negri - Doutorado em Economia pela Universidade Estadual de Campinas (UNICAMP). Mestrado em Ciência Econômica (UNICAMP).

${ }^{2}$ Doutoranda pela Universidade Federal do Estado do Rio de Janeiro (Unirio). Mestrado em Artes Cênicas pela mesma universidade. Formada em Tecnologia da Produção do Vestuário pela instituição Senai Cetiqt e Cenografia e Indumentária pela Unirio. cah.costa84@gmail.com 
Esse texto é parte da pesquisa de doutorado que está em andamento no Programa de Pós-graduação em Artes Cênicas (PPGAC/Unirio). Portanto, para que todos possam compreender a importância desse relato, é necessário fazer uma breve introdução ao tema da pesquisa que deu origem a essa reflexão.

A pesquisa tem como centro de investigação o processo criativo dos alunos dos cursos de Figurino/ Cenografia, Atuação e Direção da Unirio. Essa pesquisa é ainda, desdobramentos da dissertação de mestrado apresentada em 2019 ao PPGAC/Unirio que investigou o vestuário cênico dos personagens negros no teatro brasileiro. Na ocasião, foi apontado dentre vários aspectos a lacuna no ensino da indumentária dos povos não europeus, sobretudo os povos africanos e afrobrasileiros. Fez-se uma abordagem sobre o figurino do personagem negro e um breve panorama a partir de fragmentos do século XIX até o início do XX, mostrando curtas representações do vestuário cênico de alguns personagens negros desses períodos. No entanto, o foco da dissertação foi a criação de figurinos em montagens contemporâneas sobre as personagens negras, onde elas não eram somente coadjuvantes de outras histórias, mas sim protagonista de suas narrativas.

Durante a análise de três espetáculos ligados às estéticas do teatro negro no Brasil, ficou subentendido que há uma lacuna na formação dos profissionais responsáveis por assinar as visualidades da cena, profissionais que um dia foram alunos em cursos de cenografia, figurino ou artes visuais. Entendeu-se que a formação desses alunos se deu a partir das estéticas europeias e ao se deparar com a imagem dos personagens negros o que se tem são referências de corpos escravizados, marginalizados, subalternos e estigmatizados.

Em relação às fontes que normalmente são utilizadas no processo de criação, detectamos que são poucas, tais como pesquisas, publicações, livros, acervos e museus que em vias de levantamentos históricos servem de arcabouços para fins de pesquisas voltadas para o corpo negro. Isso interfere diretamente no processo criativo dos profissionais que vestem o corpo da personagem negra.

Evidentemente que sem incentivo às produções acadêmicas (Indumentária/Figurino) sobre a cultura africana e afro-brasileira, fontes de 
pesquisas permanecerão defasadas e, ao concluir o curso, o aluno figurinista terá o seu desempenho prejudicado. Acreditamos que a ausência dessas disciplinas está aliada ao racismo estrutural que marca a sociedade brasileira e que se encontra também no espaço acadêmico (Kilomba, 2019). Assim, como elemento fundamental dessa discussão, o relato que compõe o corpo desse texto abre um debate necessário e elucidativo para os meios de educação/ensino nos cursos de Figurino e Artes Cênicas.

Sabemos que esse tema de modo geral causa desconforto e, em muitas áreas do conhecimento, após 18 anos da promulgação da Lei no 10.639/2003 que torna obrigatório o ensino da História e Cultura Afro-brasileira e africana nas disciplinas artes, história e literatura - ela ainda é motivo de longos debates. A produção de livros na área do vestuário identificado atualmente como "afrobrasileiro" é um dos mais carentes em bibliotecas públicas, livrarias e em acessos virtuais. Acreditamos que tal ausência se dá porque a historiografia oficial ainda prioriza estudos e tendências que foram introduzidas no Brasil por meio dos conceitos da moda europeia, assim como deliberadamente silencia sobre a produção africana e afro-diaspórica. Com isso, desenvolver projetos, tanto para produção de moda quanto para figurinos teatrais, tornou-se um processo no qual os pesquisadores, em geral, apresentam dificuldades para encontrar e fazer uso de bibliografias adequadas, explicitando o epistemicídio de que trata Sueli Carneiro (2005) em sua tese de doutorado.

Nas considerações finais apontadas na dissertação de mestrado (2019) apresentamos algumas hipóteses que atualmente são investigadas no doutorado. Uma delas sustenta a tese de que "a ausência de disciplinas que abordem a cultura afro-brasileira e africana no currículo dos alunos de cenografia e indumentária impactam a formação profissional dos mesmos, dificultando a elaboração de projetos que visam vestir o corpo negro na cena do teatro contemporâneo".

Como problemática, apresentamos questionamentos elaborados da seguinte forma: ferramentas didáticas aplicadas para o ensino das culturas europeias que atualmente são utilizadas nas aulas de cenografia e figurino dão conta da cultura afrodiapórica? São elas capazes de conceber imagens que correspondem a realidade do povo preto? Quais são as histórias que constroem as narrativas do 
corpo negro na cena do teatro brasileiro? Como transformar o pensamento do corpo discente e a forma de visualizar o corpo negro sem designá-lo ao lugar estereotipado que comumente o encontramos? Quais metodologias e ferramentas pedagógicas serão capazes de formar novos profissionais das visualidades da cena e garantir o saber/fazer na sua prática artística e nas concepções de trajes cênicos?

Essas questões foram levantadas porque é do nosso conhecimento que, no Brasil, o conteúdo de ensino da moda/vestuário ministrado em sala de aula tem o eixo central voltado para a moda europeia. A moda brasileira há anos é baseada nos costumes europeus, principalmente na moda francesa. Nossos pilares de ensino sempre ignoraram a moda a partir da cultura dos nossos povos, povos indígenas e povos afro-brasileiros. Assim, a cultura europeia sempre foi a norteadora dos conteúdos que preenchem as grades curriculares que, por sua vez, são o fio condutor na formação dos profissionais do vestuário. Vale ressaltar que as áreas de competências aqui citadas são interdisciplinares. Os cursos de Moda formam muitos profissionais que acabam seguindo carreira no meio artístico, bem como os cursos de Artes Visuais e História da Arte. Assim, ao longo do nosso relato será comum o diálogo com essas disciplinas em que essa problemática também se faz presente.

Acrescentamos ao que foi exposto até aqui outro fato muito importante para a apresentação dos relatos: a ideia de representatividade e inclusão. Embora o termo sobre representatividade tenha sido amplamente debatido nos últimos anos, principalmente nas redes midiáticas, a sala de aula deixa muito a desejar em relação ao assunto. Atualmente temos em sala de aula um corpo discente muito diferente do que tínhamos antes: temos alunos indígenas, alunos negros, alunos LGBTQIA+ e alunos de baixa renda. Essa nova geração de alunos já chega à universidade com pautas identitárias importantíssimas, buscam se reconhecer nos debates, nas narrativas apresentada se nos espaços onde a produção do conhecimento é validada.

Parte dos alunos que estudam a cultura e a história do vestuário como construções identitárias não se dão por satisfeitos em aprender apenas os conteúdos de culturas europeias. Digo parte dos alunos porque não são todos que 
buscam esse conhecimento, a maioria são estudantes que sentem falta dessa representatividade nos conteúdos ministrados em sala de aula, principalmente indígenas e negros que tiveram a origem de suas histórias silenciadas por muitos anos. É esse corpo discente que não aceita mais o silenciamento como realidade e busca construir suas narrativas, desvelar suas histórias, reescrever aquilo que foi apagado. Nesse novo corpo discente temos aquilo que Paulo Freire (2020) e bell hooks (2020) chamam de "educação como prática da liberdade", que se estende ao conceito básico de que não existe educação neutra. Segundo a visão de Freire, todo ato de educação é um ato político.

Nessa perspectiva, como um ato resistência, na busca por mudanças e ansiando por novos olhares e modos de vestir o corpo do personagem negro é que nasceu a pesquisa de tese que está em andamento e tem como título provisório "Reeducar o olhar, refazer a lição: A construção identitária do corpo negro por meio das visualidades da cena no processo criativo dos alunos de cenografia e figurino".

\section{Despir o olhar para vestir o corpo negro: O início da pesquisa}

Em março de 2020 daríamos início a um novo ciclo no Departamento de Cenografia e Indumentária/Unirio. Estávamos preparando o laboratório de criação de figurino voltado para o personagem negro. Era a primeira vez que o tema entrava por aquelas portas. Estávamos todos ansiosos. Os grupos de estudantes já estavam inscritos e no dia dez de março tivemos nosso primeiro encontro. Foi um encontro de escuta e desabafos. Tantos anos de silenciamento fazia parecer que tudo precisava ser dito naquele dia. A aula que duraria duas horas rendeu três.

Confesso que senti mais medo do que alegria, pois eu tinha uma responsabilidade enorme nas mãos e o receio de não dar conta. Respirei fundo e pensei: não tem mais jeito, não dá para voltar atrás. Esse voltar atrás era sobre muitas coisas. Voltar atrás e se manter no silenciamento. Voltar atrás e abaixar a cabeça quando somente as histórias europeias forem contadas. Voltar atrás e não se ver representada nos personagens negros que eram apresentados nos palcos. Não dava para voltar atrás, nunca mais.

Saímos da sala de aula com a tarefa de pesquisar mapas: iríamos trabalhar 
o semestre em cima de um mapa gigante do continente africano. Toda semana um aluno iria apresentar sua "morada" em África. Trata-se de uma dinâmica onde o aluno escolheria um lugar em África para chamar de seu. Esse lugar seria seu refúgio no mundo. Sua pesquisa começaria no lugar marcado geograficamente no mapa e se expandiria para o lugar da poesia. A ideia inicial era que os alunos se sentissem estimulados a enxergar outras Áfricas e só então, no final do processo de pesquisa e com o olhar despido, eles poderiam enfim vestir o corpo negro.

Mas nada disso foi possível, dia dezesseis de março de dois mil e vinte, parte do mundo estava parado, então o Brasil parou. Era o Sars-Cov-2, um vírus que entrou país afora e mudou os planos de muita gente. De início pensávamos que seriam apenas alguns dias, talvez semanas ou no máximo um mês. Quem não pensou? As aulas foram suspensas por seis meses e nesse tempo muita coisa mudou. Tive tempo de amadurecer o projeto de pesquisa e como aconteceram muitos eventos acadêmicos on-line, tive oportunidade de ouvir outros pesquisadores e explorar mais as ideias iniciais. Em outubro do mesmo ano as aulas foram retomadas em caráter emergencial de ensino remoto. O projeto inicial teve que ser adaptado para o ensino virtual. As aulas foram divididas em conteúdos síncronos e assíncronos, novidade para muitos professores e alunos.

Diante dessa situação tivemos que refazer o plano de ensino, as estratégias, as dinâmicas e até as expectativas de aprendizagem. Os jogos que foram montados para as aulas presenciais corriam um sério risco de não funcionar no ambiente virtual. Nessa pausa de seis meses até o início do semestre letivo, eu já ministrava aulas de figurino na Escola e Faculdade Angel Vianna (EFAV), como professora convidada e ali eu já havia passado pela experiência do ensino remoto. Portanto, muitas coisas me preocupavam, desde a adaptação das aulas práticas para o ambiente virtual até as condições de acesso dos alunos. Essa sempre foi uma questão e apesar da longa espera para a retomada das aulas, a instituição (Unirio) cuidou para que o maior número possível de alunos pudesse permanecer com suas matriculas ativas, fornecendo tablets e pacotes 4G, além de auxílios permanência.

Com muitos desafios e descobertas por vir, demos início ao semestre. Eis que a pandemia abriu possibilidades e aproveitamos o fato de estarmos no virtual 
e trouxemos convidados externos para compor o laboratório criativo. Algo que jamais iríamos imaginar era a possibilidade ter uma aula com uma professora falando conosco direto da Alemanha, outro de Salvador (BA) e uma figurinista ilustre da Rede Globo. Dessa forma, nosso planejamento foi refeito e o adaptamos de modo que nossa proposta pudesse acontecer sem se tornar maçante.

No primeiro semestre de aulas remotas tivemos 14 aulas síncronas, com atividades assíncronas e um trabalho em grupo no final do semestre. Foi um semestre atípico, porém com muito aprendizado, troca de saberes e reflexões necessárias. Algo muito prazeroso foi ver a turma repleta de alunos negros, pois se tratava de conteúdos com abordagem sobre o personagem negro. Foram dezesseis alunos inscritos, dos quais treze eram não brancos, a maioria estava ali com sede de aprendizado, eram alunos atores, diretores, cenógrafos e figurinistas. O projeto de pesquisa apresentado ao PPGAC-Unirio tem como proposta trabalhar a construção das visualidades do corpo negro em conjunto com os alunos dos outros departamentos a partir da vivência dos alunos em seus locais de origem. Assim colocamos em prática a pedagogia da cooperação que é uma pedagogia viva, participativa e envolvente.

Ainda sobre as adaptações do conteúdo das aulas, mesmo com alguns contratempos, conseguimos readaptar boa parte o ensino remoto. Uma das dinâmicas que foi possível realizar foi a de "memórias alinhavadas", que era um espaço em que o aluno selecionava o nome de um povo africano e trazia histórias para compartilhar com o grupo. Esse mesmo aluno ou outro do grupo tentava associar com algo semelhante da sua comunidade. Podia ser uma brincadeira de criança, uma dança, um som, um festejo religioso ou qualquer outra coisa, o importante era deslocar essa história no tempo, trazer para perto de nós. Usamos essa dinâmica como um dispositivo de afetos para criação, bem como para nos aproximar das histórias que não sabíamos. Mais tarde essas memórias nos serviriam de base para criação do figurino.

Os alunos sempre se mostraram muito envolvidos com as aulas, mesmo aqueles que não ligavam as câmeras de seus dispositivos, estavam sempre articulando mensagens no chat, tecendo perguntas aos convidados e contribuindo com o debate. Mas no decorrer das aulas percebemos que os alunos negros, que 
eram a maioria em sala de aula, eram também os que mais faltavam. Não fosse por esse fato, o semestre teria sido um grande sucesso. No entanto, os alunos que mais reivindicavam pelo tema, eram os mesmos que tinham que abrir mão dele para trabalhar. O primeiro ano da pandemia foi devastador para muitas famílias pobres, a maioria formada de pessoas pretas e a maioria dos alunos era de pessoas pretas.

Esse foi um contratempo que eu não esperava. Acreditava que os textos selecionados seriam cansativos, que as pesquisas seriam demais para a cabeça deles, que a empolgação da volta às aulas iria durar pouco tempo, mas não imaginei que os alunos que mais lutaram para ter esse espaço iriam ter que faltar. Foi difícil entender esse movimento. Quase toda semana um aluno enviava mensagem justificando a ausência e lamentando pelo ocorrido, mas a frase final que encerrava a mensagem era quase sempre a mesma: "Desculpa, eu preciso muito pegar esse job”.

A ausência do aluno negro em sala de aula afeta diretamente a construção da pesquisa, pois a ideia que fundamenta a tese também está associada à representação desses corpos. Não nos interessa escrever somente sobre eles, mas sim com eles e para eles. Importa-nos pensar a construção das visualidades da cena a partir do deslocamento desses corpos no espaço, pensar a imagem e a relação desses corpos que são invisibilizados e marginalizados pela nossa sociedade.

Durante o primeiro semestre letivo de 2020.1 muitas realidades foram visitadas. A realidade do aluno que precisou abrir mão de horas de estudos para sair no meio da pandemia e "fazer seu ganha pão", a realidade do aluno que precisou dividir o espaço de estudos com outras pessoas da casa, a realidade do aluno que se sentiu deprimido por não saber o que fazer, do aluno que viu sua privacidade sendo exposta, da instabilidade do sinal da internet, do equipamento que não funcionava tão bem. Essas realidades são as que nos atravessaram, nos afetaram e nos fizeram refletir muito sobre ser professor, ser aluno e ser humano. A pandemia mudou nossa forma de ver e pensar a sala de aula. Durante nossos encontros síncronos abrimos um espaço para a escuta, um espaço para o cafezinho, para a troca de saberes. Durante a pandemia o papel do professor que 
luta por uma educação descolonizada dobrou. Para levar o semestre com mais fluidez foi necessário romper com certos padrões acadêmicos, foi necessário redobrar a atenção para levar a comunicação e ter a certeza de que o ensino estava chegando do outro lado da tela.

Foram três meses construindo laços de afetos não só para criar, mas também para fortalecer nosso corpo e nossa mente em um momento de muita delicadeza. Corpo docente, corpo discente, corpo atento a tudo que estava a nossa volta. Nossas histórias, as histórias dos outros. Como ficaram essas histórias?

\title{
Experiências, Criações e Reflexões: Das tentativas aos resultados
}

\begin{abstract}
"Preto sujo!" Ou simplesmente: "Olhe, um preto!" Cheguei ao mundo pretendendo descobrir um sentido nas coisas, minha alma cheia do desejo de estar na origem do mundo, e eis que me descubro objeto em meio a outros objetos (Fanon, 2008, p. 103).
\end{abstract}

No fim de tudo, quando ao avaliar o semestre, vimos que o saldo foi positivo. O resultado veio na apresentação dos processos. Os alunos foram divididos em grupos para a construção do trabalho final. Foram quatro grupos, em cada um deles tinha um aluno do curso de Direção, um aluno de Atuação e alunos de Cenografia e Figurino. O desafio para cada grupo era montar um projeto de visualidades da cena com foco no figurino do personagem negro. Os grupos selecionaram contos infanto-juvenis de contação de histórias negras, "Amoras”, do autor Emicida (2018); "Que cabelo é esse, Bela?”, das autoras Simone Mota e Roberta Nunes (2020); "O sol na cabeça”, de Geovani Martins (2018) e o conto "Os Ibejis encontram água e salvam sua aldeia”, de Reginaldo Prandi (2019). 
Figura 1 - Processo de criação para texto "Amoras"

Colagem a partir das pranchas criativas dos alunos Elen Carvalho, Diogo Costa, Flávio Muniz e Larissa Santiago
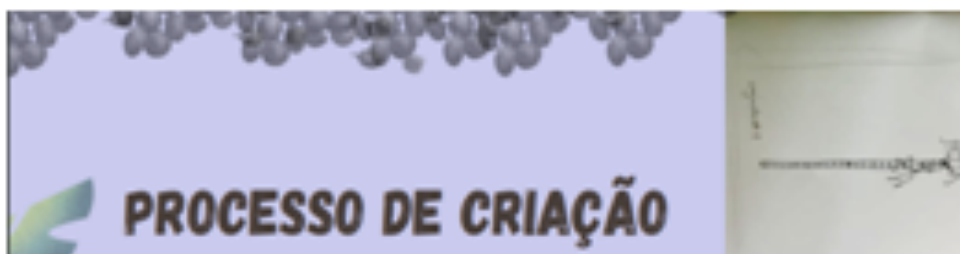

PROCESSO DE CRIAÇÃO
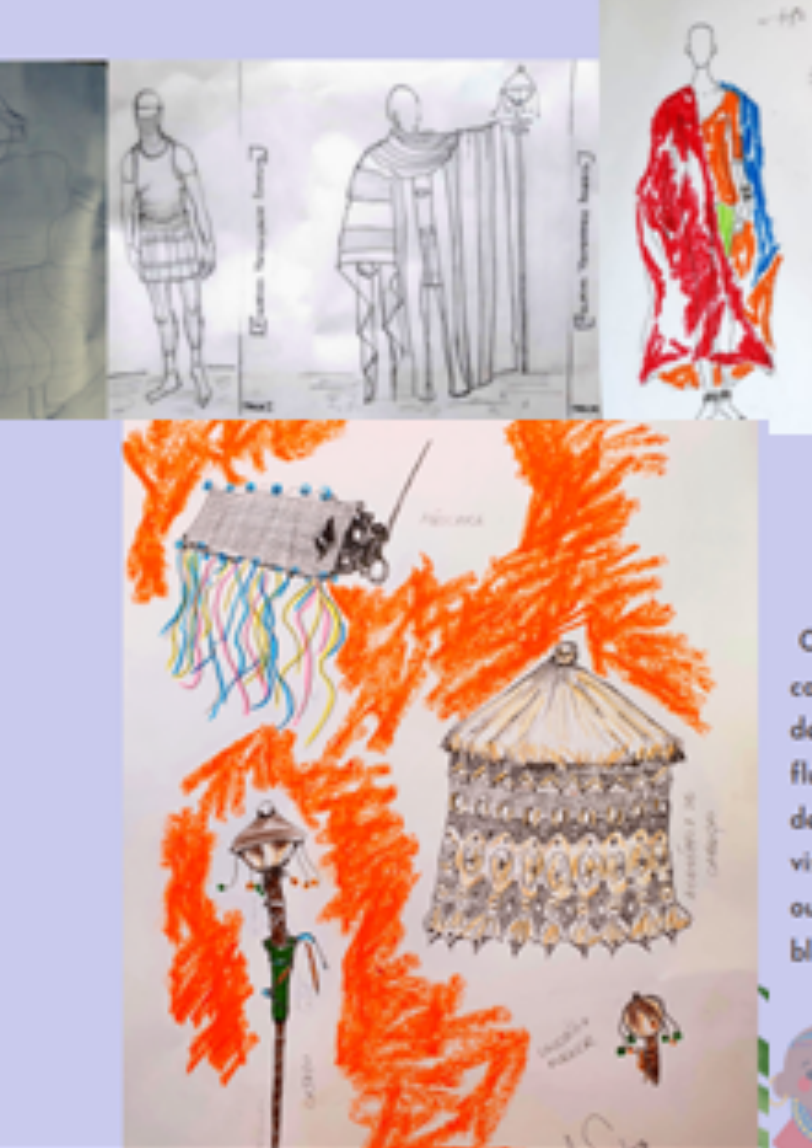

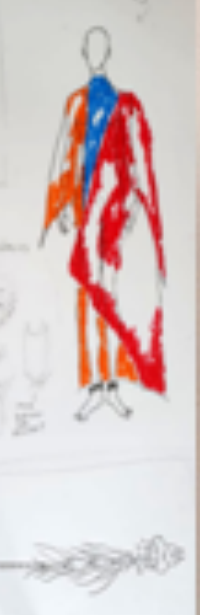

O Amoroke conto cem podeóes desenhodes a tinto fluorescente, ofim de cousor impocto visual na penumbro ou em momentes de blockout 1
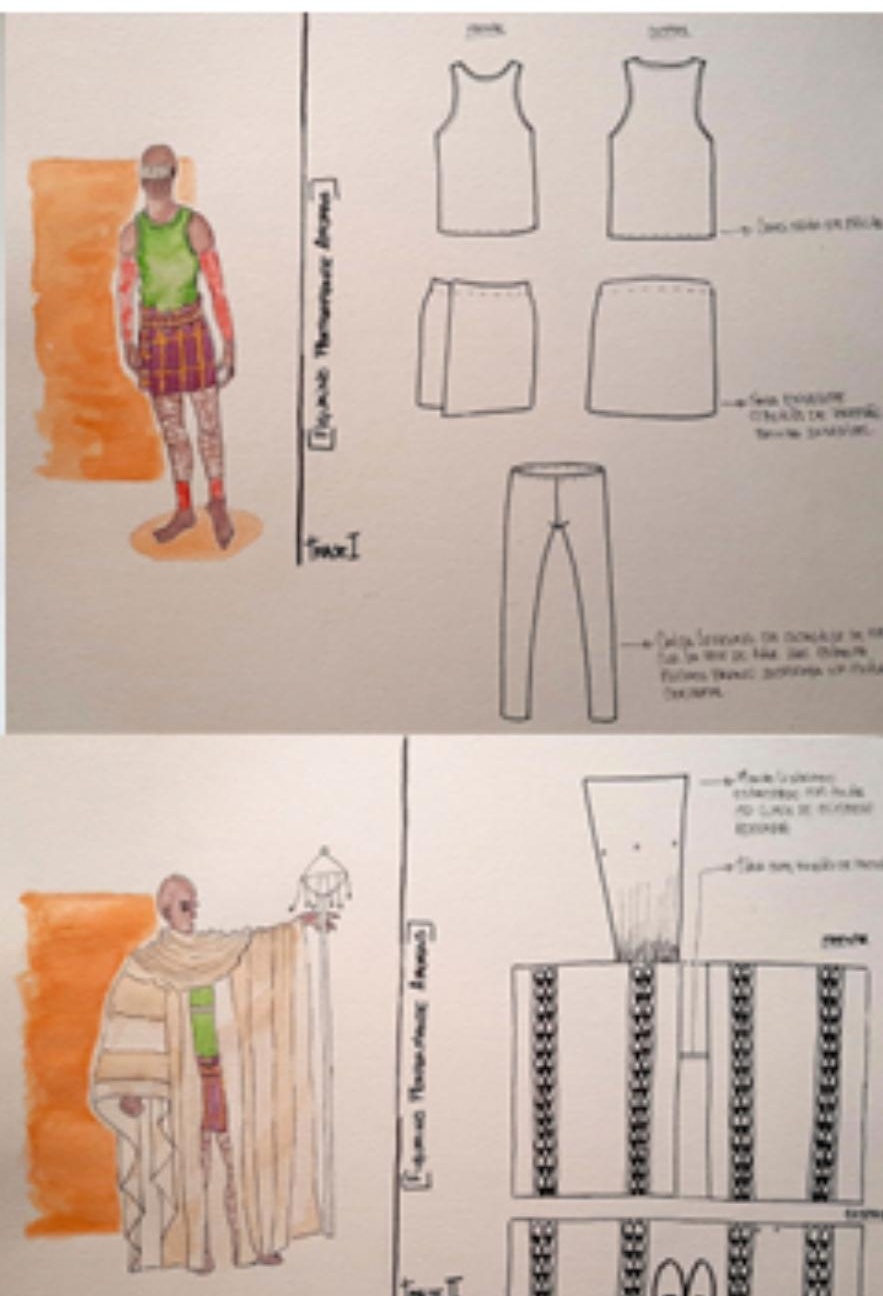

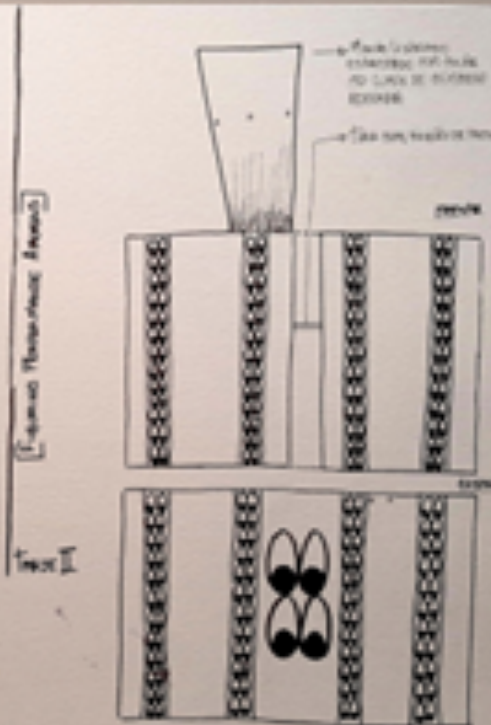


Figura 3 - Processo de criação para o texto "Os Ibejis encontram água e salvam sua aldeia" Colagem a partir das pranchas criativas dos alunos Jorge Oliveira,

Cássia Salles e Brisa Lima

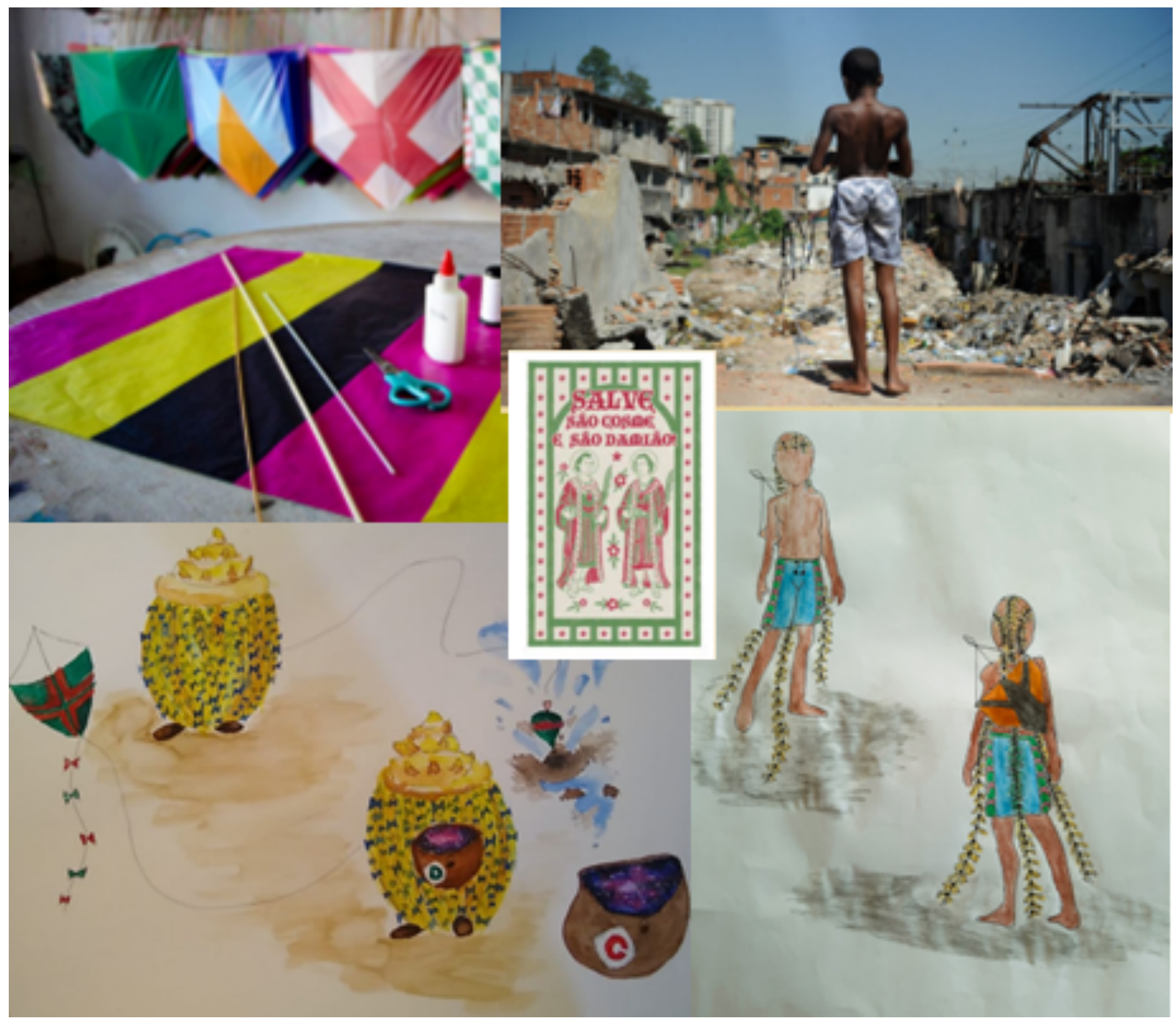

A contribuição de alunos dos outros cursos foi fundamental para a conclusão e o sucesso dessa etapa. Cada aluno contribuía com a criação do figurino de acordo com sua experiência e formação. O aluno de atuação cênica contribuía com as narrativas do seu próprio corpo. Vale ressaltar que os alunos atores eram alunos negros, assim suas trajetórias e suas vivências cotidianas eram elementos fundamentais para criação, pois serviam de dispositivos para os alunos figurinistas que iriam definir a criação final. Os alunos diretores trouxeram a experiência que 
haviam adquirido em outros processos de montagem, cooperavam com a organização da cena e com os aspectos que são necessários para dirigir e montar um espetáculo.

Nessa primeira etapa levamos em consideração, principalmente, o processo de criação, a relação de grupo, a cooperação entre as formações. O croqui final foi pontuado, mas exigimos bem menos do que normalmente cobramos nas aulas presencias onde os alunos têm espaço físico para desenhar, costurar e experimentar. No período em que estavam sendo desenvolvidos os projetos houve caso de alunos que foram contaminados com a Covid-19. Um dos grupos teve dois membros desfalcados, uma ficou internada em estado grave, outra perdeu o emprego e teve que se mudar para o interior do Rio de Janeiro, onde não dispunha de internet o tempo todo e, para fazer as chamadas dos encontros virtuais com o grupo, ela tinha que se deslocar até o centro da cidade onde estava morando.

Como relatamos anteriormente, muitas dificuldades foram surgindo ao longo do caminho. A pandemia foi muito além do que podíamos imaginar. Apesar disso, todos os alunos conseguiram finalizar com sucesso seus projetos. Trouxemos uma banca externa para avaliar e contribuir com críticas construtivas. Tereza Nabuco, a primeira figurinista negra da Rede Globo esteve presente e se emocionou com o resultado. A presença dela foi marcante desde a primeira vez em que ela esteve conosco para ministrar uma aula sobre o teatro infantil. Ela trouxe suas contribuições mostrando seu processo de criação no espetáculo negro infantojuvenil Ombela (2020), pelo qual recebeu diversas indicações e prêmios pelos figurinos. Apesar das adversidades e contratempos impostos pela pandemia, só foi possível promover esse encontro porque aprendemos a trabalhar com novas ferramentas.

A pandemia levou vidas preciosas, tirou de nós pessoas queridas, amores de muitas famílias, mas buscamos formas de transformar essas perdas nos aproximando de pessoas que outrora nos pareciam distantes. No início foi difícil entender tudo que acontecia a nossa volta, o medo parecia não ter fim. Mas foi possível e, na medida do podíamos fazer, fizemos.

No final do semestre, solicitamos aos alunos que escrevessem um parecer 
sobre a experiência que eles tiveram, boas ou ruins. O relato do aluno de direção Júlio Ângelo é bem sensível e diz o seguinte:

\begin{abstract}
Um dos principais desafios do trabalho foi manter uma comunicação estável entre os membros do grupo [...]. Com o texto escolhido, acredito que fomos mais certeiros nas nossas ambições individuais e por fim, coletivas. As sugestões de cada um se faziam como um reflexo de um desejo estético muito próprio de si. Esse fato me deu muita alegria, pois pude perceber em detalhes o que a criação em comum se tornava e se tornou. Foi fundamental termos tido contato com os grupos étnicos apresentados em nossos encontros. Sem essa pré-condição de trabalho faltaria o material necessário para sairmos de um "lugar comum" durante o processo criativo. Não falo de uma "exoticidade" na criação, falo sim da "complexidade" ao se desenvolver a criação de figurinos para a personagem negra, resgatando um diálogo ativo com as tradições e culturas africanas. A pluralidade estética e cultural que permeia as características dos grupos étnicos recusa qualquer tentativa leviana de se pautar a personagem negra, pois aqui o "negro" ganha outras infindáveis interpretações e sentidos, assentados em caminhos de liberdade ( Relatório dos discentes, Júlio Ângelo, 2020).
\end{abstract}

O relato de Júlio Ângelo é muito importante para a nossa pesquisa, pois ele, além de ser aluno veterano no curso de Teatro, ele é negro e já presenciou cenas conflituosas dentro da Unirio, episódios de racismo, assédios e silenciamento do corpo discente. O retorno dele acende uma esperança possível.

O relato a seguir é da aluna Yasmin Cardoso, ela era uma das três alunas brancas, seu relato era muito importante porque a construção desse conteúdo não apenas pensando na representatividade dos corpos negros, mas também na formação do aluno cenógrafo e figurinista. A construção do conteúdo perpassa pela ética e respeito ao outro. Yasmin Cardoso escreveu o seguinte trecho:

A proposta da disciplina para o trabalho final foi muito enriquecedora. Não só a ideia de trabalhar com histórias infantis, mas também criar um figurino em conjunto com outros colegas. Foram duas experiências totalmente novas para mim. A dinâmica de criar em grupo é muito interessante, pois nos fornece outras perspectivas que sozinhos jamais pensaríamos. Meu grupo transformou completamente o conto de Geovani Martins, que para começar nem mesmo era um conto infantil. As trocas de ideias e a vontade de fazer algo grandioso mesmo em meio a nossa simplicidade foram muito proveitosas. Assim como a oportunidade de pesquisar os povos africanos para, de alguma maneira, aproximá-los de nossa realidade e transformar nossos figurinos. Foi muito bom experimentar e me aproximar de outras narrativas, ouvir e 
contemplar a beleza de outros povos (Relatório discente, Yasmin Cardoso, 2020).

\section{Considerações Finais}

O fato de estarmos aqui e que eu esteja dizendo essas palavras, já é uma tentativa de quebrar o silêncio e estender uma ponte sobre nossas diferenças, porque não são as diferenças que nos imobilizam, mas o silêncio. E restam tantos silêncios para romper! (Lorde, 1980).

A colonização criou uma dívida impagável com os negros e indígenas da nossa sociedade, indivíduos que foram e são historicamente subjugados em virtude da raça. E, criada na colonização, a sociedade brasileira ainda espelha padrões não condizentes com a massa de sua população, ancorando-se em ideais estéticos, políticos, culturais e religiosos concebidos por indivíduos brancos colonizadores, gerando desigualdades e traumas (Kilomba,2019).

Dessa forma, no que se refere ao campo das artes, se na história da arte brasileira o padrão é o sujeito branco e a lógica corrente é de pessoa negras serem representadas (como objeto) e não representantes (como sujeitos). Todavia, há indivíduos negro descendentes na busca para estabelecer outros padrões epistemológicos que não se pautam em uma versão única da história (Adichie, 2019).

Cientes disso, não nos restam dúvidas sobre o quanto crescemos nesses últimos tempos. Tempos difíceis que nos levaram a outros lugares. Fomos forçados a mudar a rota e refazer nossos planejamentos. Poderia ter sido de outra forma, muitas outras formas, mas foi assim, do jeito que foi relatado aqui. Em meio aos prantos, às perdas, às incertezas, aos desmontes das universidades públicas que vêm sofrendo com ataques extremistas de um péssimo governo e apesar de tudo isso, nos posicionamos, restabelecemos nossas forças e caminhamos. É em função dessas reflexões que queremos participar da construção da universidade que oferece uma educação em que as pessoas vão se completando ao longo da vida, uma educação capaz de ouvir as pessoas e a partir de suas narrativas, participar dessa realidade, discutindo-a e colocando como 
perspectiva a possibilidade de mudar/somar essa realidade.

Novas perspectivas foram lançadas. Queremos colocar o corpo negro e a personagem negra no lugar de destaque, assim como outros corpos dissidentes. Nós, professores e alunos, somos responsáveis pelas pequenas e grandes transformações que ocorrem no mundo que está a nossa volta. E, apesar de todas as dores deixadas pela pandemia, estamos aqui relatando nossas histórias.

\section{Referências}

ADICHIE, Chimamanda Ngozi. O perigo de uma história única. São Paulo: Cia das Letras, 2019.

CARNEIRO, Aparecida Sueli. A construção do outro como não-ser como fundamento do ser. 2005. Tese (Doutorado em Educação) - Universidade de São Paulo, São Paulo, 2005.

FANON, Franz. Pele Negra, Máscaras Brancas. Salvador: EDUFBA, 2008.

FREIRE, Paulo. Educação como prática da liberdade. Rio de Janeiro: Paz \& Terra, 47르 Ed, 2020.

FREIRE, Paulo. Pedagogia da Autonomia: saberes necessários à prática educativa. Rio de Janeiro: Paz \& Terra, 66a Ed, 2020.

Hooks, Bell. Ensinando a transgredir: a educação como prática da liberdade. São Paulo: Martins Fontes, 2020.

KILOMBA, Grada. Memórias da Plantação: episódios de racismo cotidiano. Rio de Janeiro: Cobogó, 2019. 